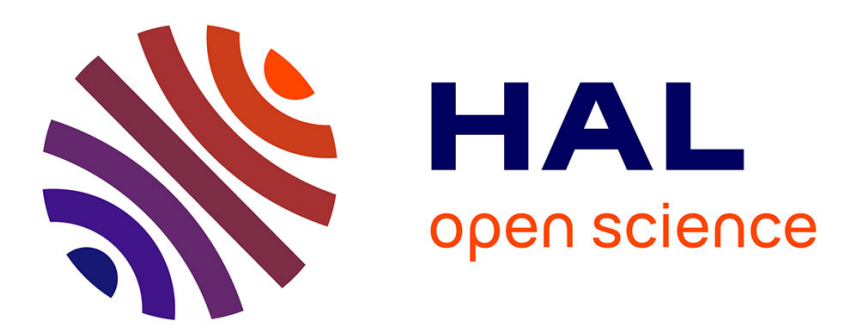

\title{
A theoretical framework for volcanic degassing chemistry in a comparative planetology perspective and implications for planetary atmospheres Fabrice Gaillard, Bruno Scaillet
}

\section{- To cite this version:}

Fabrice Gaillard, Bruno Scaillet. A theoretical framework for volcanic degassing chemistry in a comparative planetology perspective and implications for planetary atmospheres. Earth and Planetary Science Letters, 2014, 403, pp.307-316. 10.1016/j.epsl.2014.07.009 . insu-01056954

HAL Id: insu-01056954

https://hal-insu.archives-ouvertes.fr/insu-01056954

Submitted on 21 Aug 2014

HAL is a multi-disciplinary open access archive for the deposit and dissemination of scientific research documents, whether they are published or not. The documents may come from teaching and research institutions in France or abroad, or from public or private research centers.
L'archive ouverte pluridisciplinaire HAL, est destinée au dépôt et à la diffusion de documents scientifiques de niveau recherche, publiés ou non, émanant des établissements d'enseignement et de recherche français ou étrangers, des laboratoires publics ou privés. 


\title{
A theoretical framework for volcanic degassing chemistry in a comparative planetology perspective and implications for planetary atmospheres
}

Fabrice Gaillard $^{1 *} \&$ Bruno Scaillet ${ }^{1}$

${ }^{1}$ Institut des Sciences de la Terre d'Orléans, CNRS/Université d'Orléans/BRGM, 1a rue de la Férollerie 45071, Orléans cedex 2, France.* gaillard@ cnrs-orleans.fr

\begin{abstract}
:
Magmatic degassing is ubiquitous and enduring, yet its impact on planetary surficial chemistry and how it may have varied among planetary systems remain both imprecise. A large number of factors are likely to be involved in the control of magmatic gas compositions, leading roles being given to the redox state and volatile abundances in planetary interiors, and the fate of the latter during mantle melting. We however show that the pressure at which degassing occurs, that is the atmospheric pressure in most sensible cases, has a prime influence on the composition of subaerial volcanic gases on planets: High surface pressure produces $\mathrm{N}_{2}$ and $\mathrm{CO}_{2}$-rich and dry volcanic gases, while low pressure promotes sulfur-rich gases; In between, atmospheric pressures close to 1 bar trigger volcanic gases dominated by $\mathrm{H}_{2} \mathrm{O}$. This simple pattern broadly mirrors the atmospheres of VenusEarth-Mars-Io planetary suite and constitutes benchmarks for the prediction and interpretation of atmospheric features of extra-solar planets. Volatile abundances within the planetary body interiors also matter but they play a secondary role. Furthermore, our analysis shows that any difference in redox conditions prevailing during partial melting tends to disappear with the degassing process itself, converging toward a unique -planetary oxygen fugacity- at the venting pressure.

A feedback relationship between volcanic gas compositions and atmospheric pressure implies a runaway drying during atmospheric growth; that is volcanic gases must become $\mathrm{CO}_{2}$ richer as the atmospheric mass increases. This may explain some features of the Venusian atmosphere. On Earth, impact ejection of the atmosphere and $\mathrm{CO}_{2}$-sink mechanisms, such as carbonate precipitation and plate tectonics, must have decreased atmospheric pressure allowing the reestablishment of water-rich volcanic gases.
\end{abstract}




\section{Introduction}

Planetary atmospheres are most commonly considered as of either primary or secondary in origin (Zahnle et al., 2010). The first type corresponds to atmospheres with Sun(Star)-like composition, captured during the early stages of planet growth before dissipation of the Solar nebula, giving rise to a $\mathrm{H}_{2}$ - and He-rich atmosphere equilibrated with a strongly reduced proto-magma ocean at the surface (Fig. 1; e.g., Pepin, 2006; Matsui and Abe, 1986; Hashimoto et al., 2007). The second type corresponds to any primary atmosphere left over upon processes such as hydrodynamic escape, impact erosion (Lammer et al., 2008), and to which have been added volatiles arising from either the planet interior, via degassing (Elkins-Tanton, 2008; Gaillard et al., 2011), or later meteorite/comet supply (Zahnle et al., 2010; Hashimoto et al., 2007; Schaefer and Fegley, 2010). In figure 1, several types of processes fueling secondary atmospheres are illustrated, including the Magma Ocean stage (Elkins-Tanton, 2008; Gaillard and Scaillet, 2009; Hirschmann, 2012), which progressively shifted to volcanic eruptions emitting gas equilibrated under moderately oxidized conditions (Gaillard and Scaillet, 2009; Hirschmann, 2012; Gaillard et al., 2013). Equilibration with a quasi-inert planetary surface such as on present day Mars, or with an intensive biological activity such as on Earth constitutes a final atmospheric stage which is beyond the scope of our paper. Although the relative sequence of events is broadly known (Zahnle et al., 2010), estimating the individual contribution of each process to present-day atmospheres is a hard task and still widely debated field: in particular, whether planets of the inner solar system were born dry (Albarède, 2009) or wet (Zahnle et al., 2010; Drake and Righter, 2002) is still open to discussion. For Earth, accretion simulations (Raymond et al., 2006) and geochemical features (Albarède, 2009; Drake and Righter, 2002) hint at a late veneer of volatile-rich material having $\mathrm{C}, \mathrm{H}$ and $\mathrm{N}$ isotopic ratios similar to that of primitive meteorites (Marty, 2012), which were subsequently folded into the deep Earth's mantle (Albarède, 2009). If true, such a scenario implies that the magma ocean atmosphere illustrated in Fig.1 and discussed in Gaillard and Scaillet (2009) or more recently in Hirschmann (2012), must have been erased once the late veneer had supplied most of the C-O-H-S-N terrestrial inventory (Marty, 2012). Furthermore, we can reasonably assume that the atmosphere produced during a magma ocean stage must have had a small mass as most volatiles (C-O-H-S) would be contained in the huge molten reservoirs (silicate and metal; Dasgupta et al., 2013; Roskoz et al, 2013). It is therefore critical to address the mechanisms giving rise to the secondary volcanic atmosphere (Fig.1) that resulted from igneous degassing once the late veneer has been incorporated in the mantle.

As illustrated on figure 1, a fundamental source of secondary atmospheres to all planets of significant size is magmatic degassing (Elkins-Tanton, 2008; Albarede, 2009; Gaillard and Scaillet, 2009; Hirschmann, 2012; Gaillard et al., 2013; Stanley et al., 2011). Within this context, it is during 
the late accretion steps, after the dissipation of the solar nebula and core segregation, hence from an already oxidized mantle (Trail et al., 2011), that magma degassing began to significantly impact the atmosphere (Gaillard et al., 2013; Fig.1). We consider that this degassing results from basalts formed by partial melting of a mantle that has already ingested the late veneer. This is the starting point of our analysis. To the best of our knowledge, the major volatiles released by planetary basalts belong to the C-O-H-S system as these atoms can be stored at significant concentration levels in the source regions of basalts and constitute $>90 \%$ of magmatic gas produced on Earth (Symonds and Reeds, 1993), whereas other volatile species exist at much lower concentrations (Marty, 2012). In spite of a relatively poor knowledge of its behavior in magmatic system, we added nitrogen species in a few selected calculations in order to broadly illustrate the behavior of this important component of terrestrial atmosphere (Libourel et al., 2003; Russel and Arndt, 2005; Marty, 2012). Minor species not included in our approach are (1) the halogens $(\mathrm{F}, \mathrm{Cl}, \mathrm{Br} . .$.$) , the reason being that their solubility$ behavior (ie the fugacity-composition relationships) in basalts remains unknown _but we recognize their likely high importance in the magmatic degassing of Martian volcanoes (Filiberto and Treiman, 2009),_(2) noble gases, since both their abundances in the Earth mantle (Marty, 2012) and their solubilities in basalts (Libourel et al., 2003; Miyazaki et al., 2004; Iacono-Marziano et al., 2010) are negligible; for example, argon solubility is 100 times lower than that of $\mathrm{CO}_{2}$.

Magmatic volatiles may be categorized into either reduced $\left(\mathrm{CO}, \mathrm{H}_{2}, \mathrm{H}_{2} \mathrm{~S}\right)$, as when originated from a metal-saturated magma ocean (Gaillard and Scaillet, 2009; Morizet et al., 2010; Hirschmann, 2012), or oxidized $\left(\mathrm{H}_{2} \mathrm{O}, \mathrm{CO}_{2}, \mathrm{SO}_{2}\right)$, as when emitted by magmatic suites from an already differentiated body (Gaillard et al., 2013), which is the case of interest here (Fig. 1). Estimates of volatile contents in basalts produced by planetary mantles, either direct (Marty, 2012; Stanley et al., 2011; Saal et al., 2002, 2008; Hauri et al., 2011) or indirect (Gaillard et al., 2013; Kerber et al., 2009; McCubbin et al., 2010), are of a few thousand ppm at best for each of the major volatiles, with only moderate differences between planetary bodies (leaving aside the magmatism from subduction zones, which should not be viewed as mantle degassing but a by-product of shallow recycling: Wallace, 2005). However, all of this resulted in a wide range of atmospheres: Earth is characterized by high water abundance, atmospheric pressure at 1 bar, an $\mathrm{N}_{2}-\mathrm{O}_{2}$-rich atmosphere, and most carbon stored in carbonate rocks. It sharply contrasts with the dry and hot Venus and its 92 bar of moderately reduced atmosphere dominated by $\mathrm{CO}_{2}$, and containing about 3 bar (3.5\%) of $\mathrm{N}_{2}$ (Lecuyer et al., 2000; Chassefiere et al., 2012), but also with Mars which, although once flowed by water, is nowadays covered by sulfate deposits, with 0.007 bar of atmospheric pressure and an oxidized surface (Gaillard et al., 2013; Jakosky and Phillips, 2001). 
In addition to heliocentric distance, one obvious possibility to explain such a diversity is to relate it with long gone processes, such as changes in the luminosity of the Sun, chondritic bombardments, intensity of the magnetic field, solar wind erosion, each of which has clearly played a role on atmosphere evolution (Pepin, 2006; Lammer et al., 2008; Raymond et al., 2004; Chassefiere et al., 2012; Jakosky and Phillips, 2001; Kasting, 1988; Kasting and Catling, 2003; Wordsworth et al., 2013). So far, most discussions on the contrast in the physical and chemical status of planetary atmospheres have been conducted in the framework of the above mentioned processes. Another route, though not exclusive of the former, is to model the planet and its atmosphere as a closed system and to seek for a parameter that controls volcanic gas compositions, and which could vary among planets. This is the new view taken here: specifically, we explore the role of pressure on basalt degassing at the scale of the inner Solar system and we conclude that pressure of degassing, which is the atmospheric pressure in most sensible cases, has a key influence of the composition of volcanic gases emitted into the atmosphere. Overall, this new paradigm allows several major differences between the atmospheres of Venus, Earth and Mars to be reappraised. In particular, our approach highlights the fact that the composition of the atmosphere, if fueled by volcanic degassing through time, as usually assumed in most models (e.g., Elkins-Tanton, 2008; Grott et al., 2011), is in a complex feedback relationships with (1) the intensity of volcanic degassing (the amount of extrusive basalts produced), (2) the atmospheric pressure (the mass of the atmosphere and the gravity), and (3) the composition of volcanic gases. Points (1) and (2) are tightly related to the size of the planetary system and the amount of volatile species available upon mantle partial melting. Point (3) is demonstrated below.

\section{Basalt degassing in a solar system perspective}

Our approach is based on the fundamental premise that basalt is the average silicate magma erupted from rocky planets. The evolution of $\mathrm{H}_{2} \mathrm{O}$ and $\mathrm{CO}_{2}$ during basalt ascent can be rigorously modeled, with the assumption of gas-melt equilibrium (Iacono-Marziano et al., 2013). The effect of sulfur and redox conditions is treated following Gaillard and Scaillet (2009) and Iacono-Marziano et al., (2012) that is an updated equivalent of earlier methodologies (i.e. Moretti and Papale, 2004; Burgisser and Scaillet, 2007). Our approach, briefly recalled below, has been long known as the "Equilibrium constants and mass balance method" (see Holloway, 1987) initially described to calculate equilibria in the $\mathrm{C}-\mathrm{O}-\mathrm{H}$ system and we simply add sulfur species to the system (nitrogen is also considered in a few cases). The mole fractions of the different gas species were calculated from the thermodynamic constants of the following homogeneous reactions at $\mathrm{P}$ and $\mathrm{T}$.

$\mathrm{CO}^{[\text {[fluid] }}+1 / 2 \mathrm{O}_{2}=\mathrm{CO}_{2}{ }^{\text {[fluid] }}$ 
$\mathrm{H}_{2}{ }^{\text {[fluid] }}+1 / 2 \mathrm{O}_{2}=\mathrm{H}_{2} \mathrm{O}^{\text {[fluid] }}$

$\mathrm{CH}_{4}{ }^{\text {[fluid] }}+\mathrm{O}_{2}=\mathrm{CO}_{2}{ }^{\text {[fluid] }}+2 \mathrm{H}_{2} \mathrm{O}^{\text {[fluid] }}$

$1 / 2 \mathrm{~S}_{2}{ }^{\text {[fluid] }}+\mathrm{O}_{2}=\mathrm{SO}_{2}{ }^{\text {[fluid] }}$

$\mathrm{H}_{2} \mathrm{~S}^{\text {[fluid] }}+1 / 2 \mathrm{O}_{2}=1 / 2 \mathrm{~S}_{2}{ }^{\text {[fluid] }}+\mathrm{H}_{2} \mathrm{O}^{\text {[fluid] }}$

Melt-gas equilibria were also considered

$$
\begin{aligned}
& \mathrm{H}_{2}{ }^{\text {[fluid }]}=\mathrm{H}_{2}{ }^{\text {[melt }]} \\
& \mathrm{H}_{2} \mathrm{O}^{\text {[fluid }]}+\mathrm{O}^{2-[\text { melt }]}=2 \mathrm{OH}^{-[\text {melt }]} \\
& \mathrm{CO}_{2}{ }^{\text {[fluid }]+} \mathrm{O}^{2-[\text { melt }]}=\mathrm{CO}_{3}{ }^{2-[\text { melt }]} \\
& \mathrm{S}_{2}{ }^{\text {[fluid }]}+2 \mathrm{O}^{2-[\text { melt }]}=\mathrm{O}_{2}+2 \mathrm{~S}^{2-[\text { melt }]} \\
& 2 \mathrm{FeO}^{[\text {melt }]}+1 / 2 \mathrm{O}^{2-[\text { gas }]}=\mathrm{Fe}_{2} \mathrm{O}_{3}{ }^{\text {[melt }]} \\
& \mathrm{N}_{2}{ }^{[\text {fluid }]}=\mathrm{N}_{2}{ }^{\text {[melt }]}
\end{aligned}
$$

Equilibria (1) to (11) were simultaneously solved at every given pressure and temperature, under the requirement that the amounts of $\mathrm{H}, \mathrm{S}, \mathrm{O}$ and $\mathrm{C}$ remain constant in the system (gas+melt) and that the sum of the mole fraction in the fluid remains 1 (or the sum of each component partial pressure yields the total pressure). The graphite-present constraint was not imposed in our degassing simulation conversely to Iacono-Marziano et al. (2012), though our model checks for graphite saturation at any step. Each gas-gas equilibrium constant for equilibria (1), (2), (3), (4) and (5) is compiled in Symonds and Reed (1993), while the solubility law in the melt for $\mathrm{H}_{2}$ (eq.7), is after Gaillard et al (2003), for $\mathrm{H}_{2} \mathrm{O}-\mathrm{CO}_{2}$, (eqs.7,8) is taken from Iacono-Marziano et al., (2013) and for sulfur (eq. 9), is after O’Neill and Mavrogenes, (2002). The ferric-ferrous equilibrium (10) was computed after Kress and Carmichael (1991). The nitrogen solubility law (eq. 11) is taken from Libourel et al. (2003) and was experimentally calibrated at $1 \mathrm{~atm}$ total pressure. Its extrapolation to pressure exceeding one atmosphere is subject to caution; we therefore preferred to include eq. (11) only for specific calculations aiming at broadly illustrating the fate of nitrogen during planetary degassing. However, for most of the calculations presented here, nitrogen was not taken into account. The nitrogen speciation in the gas phase can be calculated using Symonds and Reeds (1993), which reveals that $\mathrm{NH}_{\mathrm{x}}$ and $\mathrm{NO}_{\mathrm{x}}$ species are unlikely at magmatic temperatures. $\mathrm{N}_{2}$ remaining the dominant species, other species were therefore neglected. The concentrations of reduced $\mathrm{C}$ species (e.g. $\left.\mathrm{CO}, \mathrm{CH}_{4}\right)$ in the basaltic melt was neglected in our calculations, as they are known to have very low solubilities in basaltic melts (Gaillard et al., 2003; Behrens and Gaillard, 2006; Morizet et al., 2010; Hirschmann, 2012). To summarize, our approach combines existing experimental studies performed on specific volatiles into a multi-component model, under the assumption of gas-melt equilibrium. Uncertainties 
in $\mathrm{H}_{2} \mathrm{O}, \mathrm{CO}_{2}, \mathrm{~S}$ solubilities in the melt are in the range 8-15\%, which translate into uncertainties for the calculated fugacities of $\mathrm{CO}-\mathrm{CO}_{2}-\mathrm{H}_{2}-\mathrm{H}_{2} \mathrm{O}-\mathrm{SO}_{2}-\mathrm{H}_{2} \mathrm{~S}-\mathrm{S}_{2}-\mathrm{SO}_{2}$ species of about 15-25\%, which include errors on pressure, temperature, and $\mathrm{fO}_{2}$ in addition to the volatile contents in the equilibrium melt. Our calculations (i.e. eq. 1 to 10) are calibrated on experimental data defining C-O-H solubility to $10 \mathrm{kbar}$, whereas $\mathrm{S}$ species solubilities in basalts is calibrated merely at low pressure $(1 \mathrm{bar}$, i.e. O’Neill and Mavrogenes, 2002) though, high pressure data indicates a relatively similar behavior (Righter et al., 2009). In this work, we used our model at pressure lower than 1000 bar and extrapolate it to lower pressures $(\mathrm{P}<0.1 \mathrm{MPa})$, which, however, remains valid as the fluid-melt system tends to be increasingly ideal as pressure decreases.

This model is applied here to simulate subaerial volcanic degassing under conditions covering the diversity encountered in planetary bodies of the solar system. We consider a basalt with initial volatile abundances as estimated in undegassed Mid Ocean Ridge Basalts (MORB : 600 ppm $\mathrm{CO}_{2}, 1000$ ppm $\mathrm{H}_{2} \mathrm{O}, 1000$ ppm S; Saal et al., 2004; Marty, 2012), though variable volatile contents will also be considered below. The initial oxygen fugacity of pre-eruptive magmas was imposed at 1.7 log-units below the FMQ (fayalite-magnetite-quartz) redox buffer. Such redox conditions are broadly representative of average conditions for magma produced in the solar system on differentiated bodies (Righter et al., 2006) as argued below. On Earth, it is considered that graphitesaturation during partial melting at mantle depth buffers the $\mathrm{fO}_{2}$ of mantle derived magmas (Blundy et al., 1991; Stagno et al, 2013) and this process has also been proposed for the Martian mantle (Righter et al., 2008; Stanley et al., 2011) providing a sound thermodynamic basis to the concept of average redox conditions during partial melting in the solar system. Once magmas are extracted from their source regions, crystallization and degassing occur. While crystallization can induce changes in magma redox state, these remain minor (Carmichael, 1991). In contrast, the redox state of magmas is likely to change during degassing (Carmichael, 1991; Burgisser and Scaillet, 2007; Gaillard et al., 2011; Gaillard et al., 2013; Shirayev and Gaillard, 2014). Simulations of basalt degassing with different initial $\mathrm{fO}_{2}$ show that, regardless of the redox state of their source regions, degassing basalts tend to reach $f \mathrm{O}_{2}$ similar to FMQ-2 \pm 0.5 in the pressure range 10-0.01 bar (Fig. 2). This key observation is already discussed in Gaillard et al. (2013) in the context of Martian volcanism, but it is clear that it can be extended to extrusive basalts on any planetary system, supporting the concept of average redox conditions for planetary basalts erupting on differentiated bodies. Simulations under more reducing conditions would make sulfur slightly less volatile (see Gaillard and Scaillet, 2009) than what will be discussed below; but this, in fact, reinforces our main conclusion that sulfur is the less volatile species; furthermore, this effect of more reduced initial conditions tends to be 
attenuated by the degassing process itself (Fig.2). Simulations of degassing paths starting from more oxidizing conditions would not alter our conclusions either, as sulfur degassing decreases the equilibrium $\mathrm{fO}_{2}$ of the system (Fig.2), which overall results in patterns globally similar to what we show in figure 3. We performed our calculations at pressures varying from 1000 bar to $10^{-6}$ bar (Fig.3). This range covers the pressure that is expected to prevail, or has prevailed, during subaerial degassing on terrestrial planets (Elkins-Tanton, 2008; Gaillard et al., 2013; Lammer et al., 2008; Chassefiere et al., 2012; Jakosky and Phillips, 2001; Kasting, 1988). The trends shown on Fig. 3 clearly demonstrate that the pressure at which volatiles are released exerts a first order control on volcanic gas compositions. In the range 500-50 bar, the volcanic gas is dominated by $\mathrm{CO}_{2}$ and $\mathrm{CO}$ whereas water and sulfur remain dissolved in the basaltic melt. In the pressure range $50-10^{-3}$ bar, water is the dominant gaseous component followed by $\mathrm{C}$ and S-species in equal amounts, whereas at still lower pressures sulfur-species constitute more than $40 \%$ of the gas. Both $\mathrm{SO}_{2}$ and $\mathrm{S}_{2}$ are present at low pressure with $\mathrm{SO}_{2}$ forming $30 \%$ of the gas phase at pressure $<10^{-5}$ bar. The key conclusion emerging from the trend shown in Fig. 3 is that a single basaltic source, broadly representative of planetary basalts, may emit a variety of chemical species into the atmosphere, depending solely on its pressure of venting.

Figure 4 shows the composition of volcanic gases in the C-O-H-S-N system. Excepting the addition of nitrogen, the computing methods, strategy, conditions and compositions are similar to those used in figure 3. The two plots in figure 4 illustrate two different concentrations in nitrogen in the magma source region. The lower concentration (Fig.4a) corresponds to the estimation from Marty (2012), giving C/H of about 300 (in weight) for the Earth mantle. The higher concentration is adjusted to match the present-day concentration in a Venus-like atmosphere (i.e. couple of bars for 100 bar of total pressure), which implies a $\mathrm{C} / \mathrm{H}$ ratio in the source of about 30 (in weight). As expected from the trend shown in figure 3, we can see that nitrogen, a species with a low solubility in basalts, is present in large concentration in the gas at elevated pressure of degassing (ie. more than a couple of bars) and it tends to be largely diluted in the gas if degassing occurs at lower pressure ( $<1$ bar). Given the large number of unknowns on nitrogen solubility in basalts, we do not intend to discuss further these results.

In the light of these calculations, volcanic degassing in a comparative planetary perspective is discussed below. In addition, we will consider that the mass of the atmosphere, yielding the atmospheric pressure, is governed by the total amount of volatile released by basalts, which directly correlates with the total mass of erupted basalts through times. Precipitation of carbonate minerals, geodynamic recycling (subduction processes), atmospheric loss (atmosphere erosion and impact 
ejections), all act as sinks decreasing the atmospheric mass and the pressure it applies on the planetary surface (at venting conditions).

\section{Large planetary bodies}

We first consider large planetary bodies, such as Venus and Earth (or even larger), which, despite being broadly similar in size and distance to Sun, have undergone contrasted atmospheric evolutions (Chassefiere et al., 2012; Kasting, 1988). Figure 5 specifically illustrates the wetness of volcanic gases as a function of equilibrium water content in basaltic melts for variable pressure of degassing (or atmospheric pressure). In order to assess the maximum water content of gases, only $\mathrm{H}_{2} \mathrm{O}$ and $\mathrm{CO}_{2}$ species are considered in Figure 5, (i.e. calculations are done in the oxidized C-O-H system, with $\% \mathrm{H}_{2} \mathrm{O}^{\text {gas }}=100-\% \mathrm{CO}_{2}{ }^{\text {gas }}$; considering other species $-\mathrm{H}_{2}, \mathrm{CO}, \mathrm{H}_{2} \mathrm{~S}, \mathrm{SO}_{2}, \mathrm{~S}_{2^{-}}$would reduce the $\mathrm{H}_{2} \mathrm{O}$ content in volcanic gases by $30 \%$ at maximum). Considering the case of Fig. 3 (600 ppm $\mathrm{CO}_{2}, 1000$ ppm $\mathrm{H}_{2} \mathrm{O}$ in the melt), the equilibrium gas is dominated by $\mathrm{H}_{2} \mathrm{O}$ if degassing occurs in an atmosphere having surface pressure similar to that of the Earth. In contrast, degassing of the same basalt in a dense atmosphere, such as the Venusian one, produces gas with much less water: i.e. $1 \% \mathrm{H}_{2} \mathrm{O}$ vs. $99 \% \mathrm{CO}_{2}$ for a ground pressure of 100 bar. Decreasing the melt $\mathrm{H}_{2} \mathrm{O}$ content to 500 ppm, as for a depleted MORB (Marty, 2012), results in a gas containing $50 \% \mathrm{H}_{2} \mathrm{O}$ if injected in an atmosphere of 1 bar (ground pressure), which remains at least twice as high as water emitted in a Venus-like atmosphere by an enriched MORB (which contains 5000 ppm $\mathrm{H}_{2} \mathrm{O}$; Marty, 2012). Our calculations show that volcanic gases emitted from basalts in a Venusian-like atmosphere ( 96 bar) are essentially dry and composed at 90-99\% of $\mathrm{CO}_{2}$ (and $\mathrm{N}_{2}$ Fig. 3-4-5), with $\mathrm{CO}$ and $\mathrm{SO}_{2}$ in variable but relatively small proportions depending on redox conditions (Gaillard and Scaillet, 2009).

The present-day Venusian atmosphere, which holds $4.6 \times 10^{23} \mathrm{~g}$ of $\mathrm{CO}_{2}$ (Lecuyer et al., 2000), most likely resulted from progressive atmosphere build-up by such a gas composition. It is interesting that the $\mathrm{CO}_{2}$ mass contained in the atmosphere of Venus is very close to the $\mathrm{CO}_{2}$ contained in the Earth exosphere (sediments + organic carbon) (Lecuyer et al., 2000). This observation must however be cautiously considered since we have little constraints on how much carbonates is contained in the Venusian crust and subsurface, which is exposed to 90 bar of $\mathrm{CO}_{2}$. The time needed to develop such a dense $\mathrm{CO}_{2}$ atmosphere is computed following Grott et al. (2011) in figure 6 considering variable magma production rates $\left(\mathrm{km}^{3} /\right.$ year). We simulate here the degassing occurring during the first events of basaltic production and we consider that the atmosphere existing before this event is negligible (ie. $<0.01$ bar). The lowest magma production rate corresponds to present-day Earth while highest rates correspond to early stages of a hot infant planet. In all cases, 
we considered a degassing from basaltic melts having $600 \mathrm{ppm} \mathrm{CO}_{2}$. A C-richer mantle source, as suggested from a recent geochemical survey (Marty, 2012), would not modify the following conclusions, it would essentially accelerate the process we describe. For instance, an Earth-sized planet having a global volcanic activity 10 times greater than that of present-day Earth (250 $\mathrm{km}^{3} /$ year), would build an atmosphere of 100 bar $\mathrm{CO}_{2}$ within less than 100 million years; a basalt with twice as much $\mathrm{CO}_{2}$ would decrease the duration to 50 million years. The fact that such volcanic gases also release $\mathrm{H}_{2} \mathrm{O}$ under the conditions defined in Fig. 5 is illustrated by the dashed lines in Fig.6. Water vapor would effectively contribute to the increase in atmospheric pressure, but its effect becomes vanishingly small as soon as the atmospheric pressure reaches a few bar, because the water content in the volcanic gas becomes too low, as explained before (Fig.5). The fundamental consequence of the pressure - gas composition relationships is that there is a feedback effect operating during the supply of volcanic gases to the atmosphere. The composition of the gas expelled must shift as the atmosphere is growing (Fig.5-6), from water-rich, when emitted in a tenuous atmosphere $\left(<1 \mathrm{bar}\right.$, in the earliest steps), to almost dry and pure $\mathrm{CO}_{2}$ once atmosphere pressure exceeds 20 bar. Assuming a steady volcanic emissions rate of $250 \mathrm{~km}^{3} /$ year, the average volcanic gas composition would evolve from $75 \%$ to less than $10 \% \mathrm{H}_{2} \mathrm{O}$ within 100 million years of degassing activity, the latter being 3 to 6 times less $\mathrm{H}_{2} \mathrm{O}$-rich than non-subduction related volcanic gases emitted today on Earth (Symonds et al., 1994). The amount of water released during such a scenario (at 100 million years) is $3 \times 10^{19} \mathrm{~kg}$, or about $3 \%$ of the Earth's hydrosphere mass, which is dominated by the oceans $\left(3 \times 10^{19} \mathrm{~kg}\right.$ is in fact equivalent to the mass of fresh water, that is ice + groundwater + rivers + lakes). Leaving such a system free to degass during 1 billion years results in volcanic gases having less than $1 \%$ of water. Higher volcanic eruption rates, such as during early planetary processes or basalts with $\mathrm{CO}_{2}$ contents higher than $600 \mathrm{ppm}$, would only accelerate this drying process leaving the accumulated amount of water delivered to the atmosphere almost unaffected. Therefore, the expected evolution of the atmosphere of a Venus/Earth-sized planet, whose outer shell would be ruled by volcanic gases emissions only, is to become dry. A small amount of water in volcanic gases with $\mathrm{H}_{2} \mathrm{O} / \mathrm{CO}_{2}$ ratios close to 1 can be delivered only in the earliest stages of degassing unless some mechanism that sinks $\mathrm{CO}_{2}$ sets in rapidly. On Earth, precipitation of sedimentary and hydrothermal carbonates, $\mathrm{C}$ sequestration in organic matter (Holland 2006), all rocks being subsequently subducted (Sleep and Zahnle, 2001), probably prevented excessive $\mathrm{CO}_{2}$ contents in the atmosphere from being reached (Walker et al., 1981). Absence of such self-regulating mechanism would otherwise lead to an inescapable increase in atmospheric pressure resulting in increasingly dry volcanic gases, i.e. a runaway growth in atmospheric $\mathrm{CO}_{2}$. Why the Earth's atmosphere pressure is low, hence its surface water-rich, and why 
this is not the case for Venus remain open questions (Kasting, 1988; Smrekar and Sotin, 2012; Chassefiere et al., 2012; Wordsworth and PierreHumbert, 2013). The classical scenario for Venus is that of the runaway greenhouse whereby elevated temperatures of the Venusian atmosphere, arising from its closer proximity to the Sun along with already abundant water, maintained water in the gaseous state (i.e. the ocean could not rain out), which in turn favored its photodissociation at high atmospheric levels followed by $\mathrm{H}$ (and to a lesser extent $\mathrm{O}_{2}$ ) loss toward space (Kasting, 1988). The conditions allowing enhanced $\mathrm{H}$ escape to space have been recently defined in Wordsworth and PierreHumbert (2013). These conditions are complex functions of the mass, composition, and temperature of the atmosphere, being in addition sensitive to the heat received from the star. Another possibility is that Venus had a lower initial water endowment relative to Earth (Chassefière et al., 2012), although N-body simulations predict that blocks, which accreted to build these planets, came from similar feeding zones of the Solar system (Raymond et al., 2004), hence had globally similar volatile contents. In either case, our calculations show that the supply of large quantities of water to an atmosphere similar to that of present-day Venus by volcanic degassing demands atmospheric pressures lower than 5 bar for a long time. This conflicts with the growing rate of the volcanic atmosphere illustrated in Fig. 6 for large planets, which is shown to rapidly lead to high surface pressure. Venus may, however, have possessed in its early history a $\mathrm{H}_{2} \mathrm{O}-\mathrm{CO}_{2}$ atmosphere with a $\mathrm{H}_{2} \mathrm{O} / \mathrm{CO}_{2}$ ratio close to unity (see Figure 6 for short durations of degassing). This initial volcanic water supply, which remains small in comparison to the Earth's ocean mass, may have been lost to space via hydrodynamic escape, as Venus's current D/H atmospheric ratio seems to imply (Kasting, 1988; Donahue, 1999; Chassefiere et al., 2012; Wordsworth and PierreHumbert, 2013). All in all, the control of volcanic gas compositions by the atmospheric pressure, which has never been considered before, demands the formation scenarios and mechanisms of evolution of planetary atmospheres to be re-assessed.

A possible scenario coupling atmospheric pressures, global geodynamics and the chemical composition of volcanic emissions is as follows: if release of an $\mathrm{H}_{2} \mathrm{O}$-rich gas is a pre-requisite for a sustainable $\mathrm{H}_{2} \mathrm{O}$-rich atmosphere then it implies that Earth must have reached clement atmospheric conditions (pressure lower than a few bar) very early in its evolution and that this pressure has remained since steady (as suggest by Som et al., 2012 for the Archean era). A late Moon forming impact, or other similar events, may have removed a large part of the early Earth's atmosphere (Genda and Abe, 2005) or the early Moon may have captured or extracted a significant part of the Earth's atmosphere (Hauri et al., 2011), either processes acting to decrease atmospheric pressure down to levels at which water is efficiently outgassed from erupted magma. Impact loss or Moon capture of the atmosphere means a chemically open system that would allow deviating from the 
runaway drying scenario shown on figure 6. Once enough water has been outgassed, atmospheric $\mathrm{CO}_{2}$ could have been sequestered in sedimentary and hydrothermal carbonates. Subduction of these carbonates, if this geodynamic process initiated from the beginning, may also have buffered atmospheric $\mathrm{CO}_{2}$ to low pressures (Walker et al., 1981; Sleep and Zahnle, 2001).

The atmospheric evolutions connected to the volcanic degassing discussed above are summarized as a flowchart in figure 7, showing in particular the atmospheric evolution paths during open vs. closed systems such as impact ejections or volatile cycling via carbonate precipitation or subduction processes. While we merely have discussed the relationships between atmosphere growth-volcanic degassing on large bodies, figure 7 also illustrates the development of tenuous atmospheres typically forming around small planetary bodies such as Mars and Io, which are now further considered below.

\section{Small planetary bodies}

Both Mars and Io illustrate the lower end of the pressure spectrum encountered on rocky planets or satellites of the Solar system for which a protracted silicate magmatic activity, lasting to nowadays for Io, can be demonstrated. According to our calculations (Fig.3-4), bodies with a low prevailing atmosphere should produce volcanic gases dominated by sulfur in contrast to Earth, where a significant part of sulfur remains in the basalt (ie. Self et al., 2006). Mars, though having a presentday $\mathrm{CO}_{2}$-rich atmosphere, is covered by widespread sulfate deposits (King and McLennan, 2010; Gaillard et al., 2013), hinting at a volcanic source in the recent past (Halevy et al., 2007; Gaillard and Scaillet, 2009; Gaillard et al., 2013). There is a profuse literature documenting the possible and widespread occurrence of liquid surface water in the early Mars (Jakosky and Phillips, 2001), which requires warming via a greenhouse gas (Fasset and Head, 2011) that could have been facilitated by either $\mathrm{CO}_{2}$ (Forget and PierreHumbert, 1997) or $\mathrm{SO}_{2}$ (Halevy et al., 2007). As far as $\mathrm{H}_{2} \mathrm{O}-\mathrm{CO}_{2}$ outgassing is concerned, the critical point is that most scenarii of past Martian atmospheres (Stanley et al., 2011; Grott et al., 2011) back calculate atmospheric pressures lower than a few bars, which are indeed compatible with abundant release of the magmatic water upon subaerial degassing (Fig. 3). The amount of water expected to be conveyed by basalts on Mars (0.2-0.4 wt\%, McCubbin et al., 2010; Gaillard et al. (2013)) has been fully released into the tenuous Martian atmosphere. In addition, the tenuous atmosphere of Mars must also have favored efficient outgassing of sulfur species (Fig.3). This richness in gaseous volcanic sulfur has certainly been exacerbated by the higher sulfur content of Martian basalts relative to those on Earth (Righter et al., 2009; Gaillard et al., 2013), but as shown in Gaillard et al. (2013), sulfur-rich Martian basalts degassing at pressure higher 
than 1 bar would not produce sulfur-rich gases. Low degassing pressures (0.1-0.01 bar) would be needed for $\mathrm{SO}_{2}$-rich gases to be expelled, which is the leitmotiv of this paper.

Io is the locus of high temperature lava emissions $\left(\mathrm{T}>1300^{\circ} \mathrm{C}, \mathrm{McEwen}\right.$ et al., 1998) with associated voluminous gas plumes dominated by $\mathrm{SO}_{2}$ (i.e. $\mathrm{X} \mathrm{SO}_{2} \sim 0.7-1$ on average) with variable $\mathrm{S}_{2}$ content (Jessup et al., 2007) plus minor amounts of other species such as $\mathrm{H}_{2} \mathrm{O}, \mathrm{H}_{2} \mathrm{~S}$ and Na-, K-, Clbearing gases (Zolotov and Fegley, 1999). The presence of C-bearing gases remains uncertain. Estimates of the pressure of gas emissions (at volcanic vents) are in the range $10^{-4}-10^{-5}$ bar. Figure 3 shows that degassing of basalt with volatile abundances typical of MORBs would essentially liberate $\mathrm{SO}_{2}$ under those conditions. The S-rich composition of gas plumes on Io can therefore be broadly explained by very low pressure of volcanic gas emissions. In detail however, the concentration of $\mathrm{H}$ and C-species shown in Figure 3 exceeds $20 \%$ at pressure $<10^{-4}$ bar whereas $\mathrm{H}_{2} \mathrm{O}$ and $\mathrm{C}$-species are inferred to be present at concentration levels $<3 \%$ and $<1 \%$, respectively, in Ionian gas plumes (Zolotov and Fegley, 1999). The mismatch could be due either to dilution of the rising plume with the surrounding atmosphere, $99 \%$ of which is made of S-bearing species, and/or to the fact that basalts produced on Io are $\mathrm{H}$ - and $\mathrm{C}$-depleted relative to MORBs, as a consequence of volatiles exhaustion of the source following secular tidal-heating and related magmatism. For instance, degassing of depleted MORBs would produce gas plumes relatively close to those identified on Io (Fig. 8). Sulfur dioxide constitutes more than $50 \%$ of the gas and $\mathrm{H}_{2} \mathrm{O}$ plus $\mathrm{CO}_{2}$ constitute less than $20 \mathrm{~mol} \%$ of the gas at degassing pressure of ca. $10^{-4}$ bar. It is worth mentioning that such depletedMORBs degassing at higher pressure, e.g. typically 0.1-1 bar, produces gases dominated by $\mathrm{H}_{2} \mathrm{O}$ and $\mathrm{CO}_{2}$.

Although depleted MORBs produce gases that are close to those emitted on Io, they still have too much $\mathrm{H}_{2} \mathrm{O}$ and $\mathrm{CO}_{2}$. The best fit to Ionian volcanic gases is obtained considering basaltic melt with 3 ppm $\mathrm{CO}_{2}, 20$ ppm $\mathrm{H}_{2} \mathrm{O}$ and 1000 ppm S (Fig. 9). Such melt would releases gases perfectly matching those observed for Io. Changes in the $\mathrm{SO}_{2} / \mathrm{S}_{2}$ ratio (i.e. up to almost $100 \% \mathrm{SO}_{2}$ ) such as observed at Ionian vents can be obtained by varying one of the following parameters: an increase of $\mathrm{fO}_{2}$ by 1-log unit, an increase in total iron content, and a temperature increase of about. $100^{\circ} \mathrm{C}$, which are within the range expected for eruptions on Io (McEwen et al., 1999). In all cases, we reiterate that such volatile-depleted basalts erupting on a planet having surface (atmospheric) pressure of a few bars would still produce gases dominated by $\mathrm{CO}_{2}$ and depleted in sulfur, illumaniting once again the prime control that pressure of degassing (or atmospheric pressure) exerts on volcanic gas compositions.

\section{Conclusion}


Our current knowledge of solubility laws of major volatiles in basaltic melts allows us to reasonably predict in a simple, unifying and rigorous way the systematics displayed by planetary degassing and how it would impact atmosphere chemistries. Variations in relative volatile abundances in the source may exacerbate the predominance of one species relative to the others, as illustrated for Io here or Mars by Gaillard et al. (2013), but it is worth stressing that volcanic gas chemistry appears to be primarily governed by the atmospheric ground pressure prevailing during degassing. This fundamental thermodynamic control on volcanic gas compositions must be implemented in conceptual models of atmospheric growth in order to decipher diverging atmospheric evolutions. An important finding is that once conditions are reached for $\mathrm{CO}_{2}$-rich gases to be expelled on large planets, a runaway growth in atmospheric $\mathrm{CO}_{2}$ is probably inescapable, unless atmosphere loss during giant impact decreases atmospheric pressure and permits water-rich volcanic gases or some mechanism, such as carbonate precipitation and plate tectonics on Earth, sequesters this $\mathrm{CO}_{2}$ out of the atmosphere.

Hence, as long as a planet is magmatically active, a general rule can be delineated in which large bodies (Earth-sized) tend to have dense, $\mathrm{CO}_{2}$-rich, atmospheres, which prevents or limits the amount of degassed $\mathrm{H}_{2} \mathrm{O}$, whereas small bodies tend to have a tenuous atmosphere favoring degassing of wet and sulfur-rich acidic gases (Mars). In between, water-dominated worlds, such as on the Earth's surface, most likely prevail because their atmospheric pressure is, and has long been, close to 1 bar (Som et al., 2012), corresponding to optimum conditions for volcanic degassing of $\mathrm{H}_{2} \mathrm{O}$ from common basalts. The qualitative agreement observed between the pressure controlled sequence of release of igneous volatile species and the observed compositions of terrestrial planet's outer shells suggests that volcanic degassing controls the long term evolution of atmosphere compositions. On an extrasolar scale, the model presented here has obvious implications for the interpretation of atmospheres surrounding exoplanets (Zugger et al., 2011), since it provides a sound physico-chemical framework for their understanding. The pressure of magma degassing must be integrated in the definition of habitable zones around stars in addition to existing criteria (Kasting and Catling, 2003; Zugger et al., 2011).

\section{References.}

Albarède, F., 2009. Volatile accretion history of the terrestrial planets and dynamic implications.

Nature 461, 1227-1233.

Behrens, H., Gaillard, F., 2006. Geochemical Aspects of Melts: Volatiles and Redox Behavior.

Elements 2, 275-280. 
Blundy, J.D., Brodholt, J.P., Wood, B.J., (1991) Carbon-fluid equilibria and the oxidation state of the upper mantle. Nature 349, 321-324. DOI:10.1038/349321a0.

Burgisser, A., Scaillet, B., 2007. Redox evolution of a degassing magma rising to the surface. Nature 445, 194-197.

Carmichael, I.S.E., 1991. The redox states of basic and silicic magmas: a reflection of their source regions? Contrib. Mineral. Petrol. 106, 129-141.

Chassefiere, E., Wieler, R., Marty, B., Leblanc, F., 2012. The evolution of Venus: Present state of knowledge and future exploration. Planetary and Space Science 63-64, 15-23.

Dasgupta, R., Chi, H., Shimizu, N., Buono, A., Walker, D., 2013. Carbon solution and partitioning between metallic and silicate melts in a shallow magma ocean: implications for the origin and distribution of terrestrial carbon. Geochimica et Cosmochimica Acta 102, 191-202. doi:10.1016/j.gca.2012.10.011

Donahue, T.M., 1999. New analysis of hydrogen and deuterium escape from Venus. Icarus 141, 226235.

Drake, M.J., Righter, K., 2002. Determining the composition of the Earth. Nature 416, 39-44.

Elkins-Tanton, L.T., 2008. Linked magma ocean solidification and atmospheric growth for Earth and Mars. Earth and Planetary Science Letters 271. 181-191.

Fassett, C.I., Head, J.W., 2011. Sequence and timing of conditions on early Mars. Icarus 211. 12041214.

Filiberto J., Treiman, A.H., 2009. Martian magmas contained abundant chlorine, but little water. Geology 37, 1087-1090. doi: 10.1130/G30488A.1.

Forget, F., Pierrehumbert, R.T., 1997. Warming early Mars with carbon dioxide clouds that scatter infrared radiation. Science 278. 1273-1276.

Gaillard, F., Schmidt, B., MacCammon, C., Mackwell, S., 2003. Rate of hydrogen-iron redox exchange in silicate melts and glasses. Geochim. Cosmochim. Acta, 67, 2427-2441.

Gaillard, F., Michalski, J., Berger, G., McLennan, S.M., Scaillet, B., 2013. Geochemical Reservoirs and Timing of Sulfur Cycling on Mars. Space Science Reviews 174, 251-300.

Gaillard, F., Scaillet, B., 2009. The sulfur content of volcanic gases on Mars. Earth and Planetary Science Letters 279. 34-43.

Gaillard, F., Scaillet, B., Arndt, N.T., 2011. Atmospheric oxygenation caused by a change in volcanic degassing pressure. Nature 478. 229-232.

Genda, H., Abe, Y., 2005. Enhanced atmospheric loss on protoplanets at the giant impact phase in the presence of oceans. Nature 433, 842-844.

Grott, M., Morschhauser, A., Breuer, D., Hauber, E., 2011. Volcanic outgassing of CO2 and H2O on 
Mars. Earth and Planetary Science Letters 308. 391-400.

Halevy, I., Zuber, M.T., Schrag, D.P., 2007. A sulfur dioxide climate feedback on early Mars. Science 318. 1903-1905. doi: 10.1126/science.1147039.

Hashimoto, G.L., Abe, Y., Sugita, S., 2007. The chemical composition of the early terrestrial atmosphere: Formation of a reducing atmosphere from CI-like material. Journal of Geophysical Research-Planets 112. E05010.

Hauri, E.H., Weinreich, T., Saal, A.E., Rutherford, M.C., Van Orman, J.A., 2011. High Pre-Eruptive Water Contents Preserved in Lunar Melt Inclusions. Science 333. 213-215.

Hirschmann, M. M., 2012. Magma ocean influence on early atmosphere mass and composition. Earth and Planetary Science Letters 279, 48-57. doi: 10.1016/j.epsl.2012.06.015.

Holland, H.D., 2006. The oxygenation of the atmosphere and oceans. Philosophical Transactions of the Royal Society B-Biological Sciences 361. 903-915.

Holloway, J.R., 1987. Igneous fluids. Reviews in Mineralogy and Geochemistry 17, 211-233.

Iacono-Marziano, G., Paonita, A., Rizzo A., Scaillet, B., Gaillard F., 2010. Noble gas solubilities in silicate melts: new experimental results and a comprehensive model of the effects of liquid composition, temperature and pressure. Chemical Geology, 279. 145-157.

Iacono-Marziano, G., Gaillard, F., Scaillet, B., Polozov, A.G., Marecal, V., Pirre, M., Arndt, N.T., 2012. Extremely reducing conditions reached during basaltic intrusion in organic matter-bearing sediments. Earth and Planetary Science Letters 357, 319-326.

Iacono-Marziano, G., Morizet, Y., Le Trong, E., Gaillard, F., 2013. New experimental data and semi-empirical parameterization of $\mathrm{H} 2 \mathrm{O}-\mathrm{CO} 2$ solubility in mafic melts. Geochimica Et Cosmochimica Acta 97. 145-157.

Jakosky, B.M., Phillips, R.J., 2001. Mars' volatile and climate history. Nature 412. 237-244

Jessup, K.L., Spencer, J., Yelle, R., 2007. Sulfur volcanism on Io. Icarus 192. 24-40.

Kasting, J.F., 1988. Runaway and moist Greenhouse atmospheres and the evolution of Earth and Venus. Icarus 74, 472-494.

Kasting, J.F., Catling, D., 2003. Evolution of a habitable planet. Annual Review of Astronomy and Astrophysics 41, 429-463.

Kerber, L., et al., 2009. Explosive volcanic eruptions on Mercury: Eruption conditions, magma volatile content, and implications for interior volatile abundances. Earth and Planetary Science Letters 285, 263-271.

King, P.L., McLennan, S.M., 2010. Sulfur on Mars. Elements 6. 107-112. 
Kress, V.C., Carmichael, I.S.E., 1991. The compressibility of silicate liquids containing Fe2O3 and the effect of composition, temperature, oxygen fugacity and pressure on their redox states. Contrib. Mineral. Petrol. 108, 82-92.

Lammer, H., Kasting, J.F., Chassefiere, E., Johnson, R.E., Kulikov, Y.N., Tian, F., 2008. Atmospheric Escape and Evolution of Terrestrial Planets and Satellites. Space Science Reviews 139. 399-436.

Lecuyer, C., Simon, L., Guyot, F., 2000. Comparison of carbon, nitrogen and water budgets on Venus and the Earth. Earth and Planetary Science Letters 181, 33-40.

Libourel, G., Marty, B., Humbert, F., 2003. Nitrogen solubility in basaltic melt; Part I, Effect of oxygen fugacity. Geochimica et Cosmochimica Acta 67, 4123-4135.

Marty, B., 2012. The origins and concentrations of water, carbon, nitrogen and noble gases on Earth. Earth and Planetary Science Letters 313, 56-66.

Matsui, T., Abe, Y., 1986. Evolution of an impact-induced atmosphere and magma ocean on the accreting Earth. Nature 319, 303-305.

McCubbin, F.M., Smirnov, A., Nekvasil, H., Wang, J., Hauri, E., Lindsley, D.H., 2010. Hydrous magmatism on Mars: A source of water for the surface and subsurface during the Amazonian. Earth and Planetary Science Letters 292, 132-13.

McEwen, A.S., Keszthelyi, L., Spencer, J.R., Schubert, G., Matson, D.L., Lopes-Gautier, R., Klassen, K.P., Johnson, T.V., Head, J.W., Geissler, P., Fagents, S., Davies, A.G., Carr, M.H., Breneman, H.H., Belton, M.J.S., 1998. High-temperature silicate volcanism on Jupiter's moon Io. Science 281, 87-90.

Miyazaki, A., Hiyagon, H., Sugiura, N., Hirose, K., Takahashi, E., 2004. Solubilities of nitrogen and noble gases in silicate melts under various oxygen fugacities: implications for the origin and degassing history of nitrogen and noble gases in the Earth. Geochim. Cosmochim. Acta 68, 387401.

Moretti, R., Papale, P., 2004. On the oxidation state and volatile behavior in multicomponent gasmelt equilibria. Chemical Geology, 213, 265-280.

Morizet, Y., Paris, M., Gaillard, F., Scaillet, B., 2010. C-O-H fluid solubility in haplobasalt under reducing conditions: An experimental study. Chemical Geology 279, 1-16.

O’Neill, H.S.C., Mavrogenes J., 2002. The sulfide saturation capacity and the sulfur content at sulfide saturation of silicate melts at $1400^{\circ} \mathrm{C}$ and 1 bar. Journal of Petrology $43,1049-1087$.

Pepin, R.O., 2006. Atmospheres on the terrestrial planets: Clues to origin and evolution. Earth and Planetary Science Letters 252. 1-14. 
Raymond, S.N., Quinn, T., Lunine, J.I., 2004. Making other earths: dynamical simulations of terrestrial planet formation and water delivery. Icarus 168. 1-17.

Righter, K., Drake, M.J., Scott, E., 2006. Compositional relationships between meteorites and terrestrial planets, in: Lauretta, D., Leshin, L. \& McSween, H.Y. (Eds.), In Meteorites and the Early Solar System II, D. S. Lauretta and H. Y. McSween, Jr., eds, pp. 803-828. Univ. Arizona Press.

Righter, K., Yang, H., Costin, G., Dowrns, R.T., 2008. Oxygen fugacity in the Martian mantle controlled by carbon: New constraints from the nakhlite MIL 03346. Meteoritics \& Planetary Science, 43, 1709-1723.

Righter, K., Pando, K., Danielson, L.R., 2009. Experimental evidence for sulfur-rich martian magmas: Implications for volcanism and surficial sulfur sources. Earth and Planetary Science Letters 288, 235-243.

Roskosz, M., Bouhifd, M.A., Jephcoat, A.P., Marty, B., Mysen, B.O., 2013. Nitrogen solubility in molten metal and silicate at high pressure and temperature. Geochimica et Cosmochimica Acta $121,15-28$.

Russell M.J., Arndt N.T., 2005. Geodynamic and metabolic cycles in the Hadean. Biogeosciences 2, 97-111.

Saal, A.E., Hauri, E.H., Langmuir, C.H., Perfit, M.R., 2002. Vapour undersaturation in primitive mid-ocean-ridge basalt and the volatile content of Earth's upper mantle. Nature 419. 451-455.

Saal, A.E., Hauri, E.H., Lo Cascio, M., Van Orman, J.A., Rutherford, M.C., Cooper, R.F., 2008. Volatile content of lunar volcanic glasses and the presence of water in the Moon's interior. Nature 454, 192-195.

Shirayev, A.A., Gaillard, F., 2014. Local redox buffering by carbon at low pressures and the formation of moissanite - natural SiC. European journal of mineralogy. vol 25, n6. http://dx.doi.org/10.1127/0935-1221/2013/0025-2339.

Schaefer, L., Fegley, B., Jr., 2010. Chemistry of atmospheres formed during accretion of the Earth and other terrestrial planets. Icarus 208. 438-448.

Self, S., M., Widdowson, T., Thordarson, A. E. Jay, 2006. Volatile fluxes during flood basalt eruptions and potential effects on the global environment: A Deccan perspective. Earth and Planetary Science Letters 248, 518-532. doi:10.1016/j.eps1.2006.05.041.

Sleep, N.H., Zahnle, K., 2001. Carbon dioxide cycling and implications for climate on ancient Earth. 
Journal of Geophysical Research-Planets 106. 1373-1399

Smrekar, S.E., C., Sotin, 2012. Constraints on mantle plumes on Venus: Implications for volatile history. Icarus 217, 510-523.

Som, S.M., Catling, D.C., Harnmeijer, J.P., Polivka, P.M., Buick, R., 2012. Air density 2.7 billion years ago limited to less than twice modern levels by fossil raindrop imprints. Nature 484, 359362.

Stagno, V., Ojwang, D.O., McCammon, C.A. \& Frost, D.J. The oxidation state of the mantle and the extraction of carbon from Earth's interior. Nature 493, 84-87 (2013).

Stanley, B.D., Hirschmann, M.M., Withers, A.C., 2011. CO2 solubility in Martian basalts and Martian atmospheric evolution. Geochimica Et Cosmochimica Acta 75, 5987-6003.

Symonds, R.B, Reed, M.H., 1993. Calculation of multicomponent chemical equilibria in gas-solidliquid systems: Calculation methods, thermochemical data and applications to studies of hightemperature volcanic gases with examples from Mount St. Helens: Am. J. Sci. 293, 758-864.

Symonds, R.B., Rose, W.I., Bluth, G.J.S., and Gerlach, T.M., 1994. Volcanic-gas studies: methods, results, and applications, in: Carroll, M.R., and Holloway, J.R. (Eds), Volatiles in magmas, Reviews in Mineralogy, v. 30, p.p. 1-66.

Trail, D., Watson, E.B., Tailby, N.D., 2011. The oxidation state of Hadean magmas and implications for early Earth's atmosphere. Nature 480, 79-82.

Walker, J.C.G., Hays, P.B., Kasting, J.F., 1981. A negative feedback mechanism for the long-term stabilization of Earths surface-temperature. Journal of Geophysical Research-Oceans and Atmospheres 86, 9776-9782.

Wallace, P., 2005. Volatiles in subduction zone magmas: concentrations and fluxes based on melt inclusion and volcanic gas data. Journal of Volcanology and Geothermal Research 140, 217-240.

Wordsworth, R., Pierrehumbert, R., 2013. Water loss from terrestrial planets with CO2-rich atmospheres. The Astrophysical Journal, 778, 154-173. doi:10.1088/0004-637X/778/2/154

Zahnle, K., Schaefer, L., Fegley, B., 2010. Earth's Earliest Atmospheres. Cold Spring Harbor Perspectives in Biology, 2, a004895. DOI: 10.1101/cshperspect.a004895

Zolotov, M.Y., Fegley, B., 1999. Oxidation state of volcanic gases and the interior of Io. Icarus 141, 40-52.

Zugger, M.E., Kasting, J.F., Williams, D.M., Kane, T.J., Philbrick, C.R., 2011. Searching for water earths in the Near-Infrared. Astrophysical Journal 739, 2. DOI: 10.1088/0004-637X/739/1/12. 
Acknowledgements F.G. acknowledges the European Research Council for funding support (ERC grant number 279790). We acknowledge the helpful reviews by J. Blundy and C. Lecuyer and the editorial handling of C. Sotin.

\section{Figure Captions:}

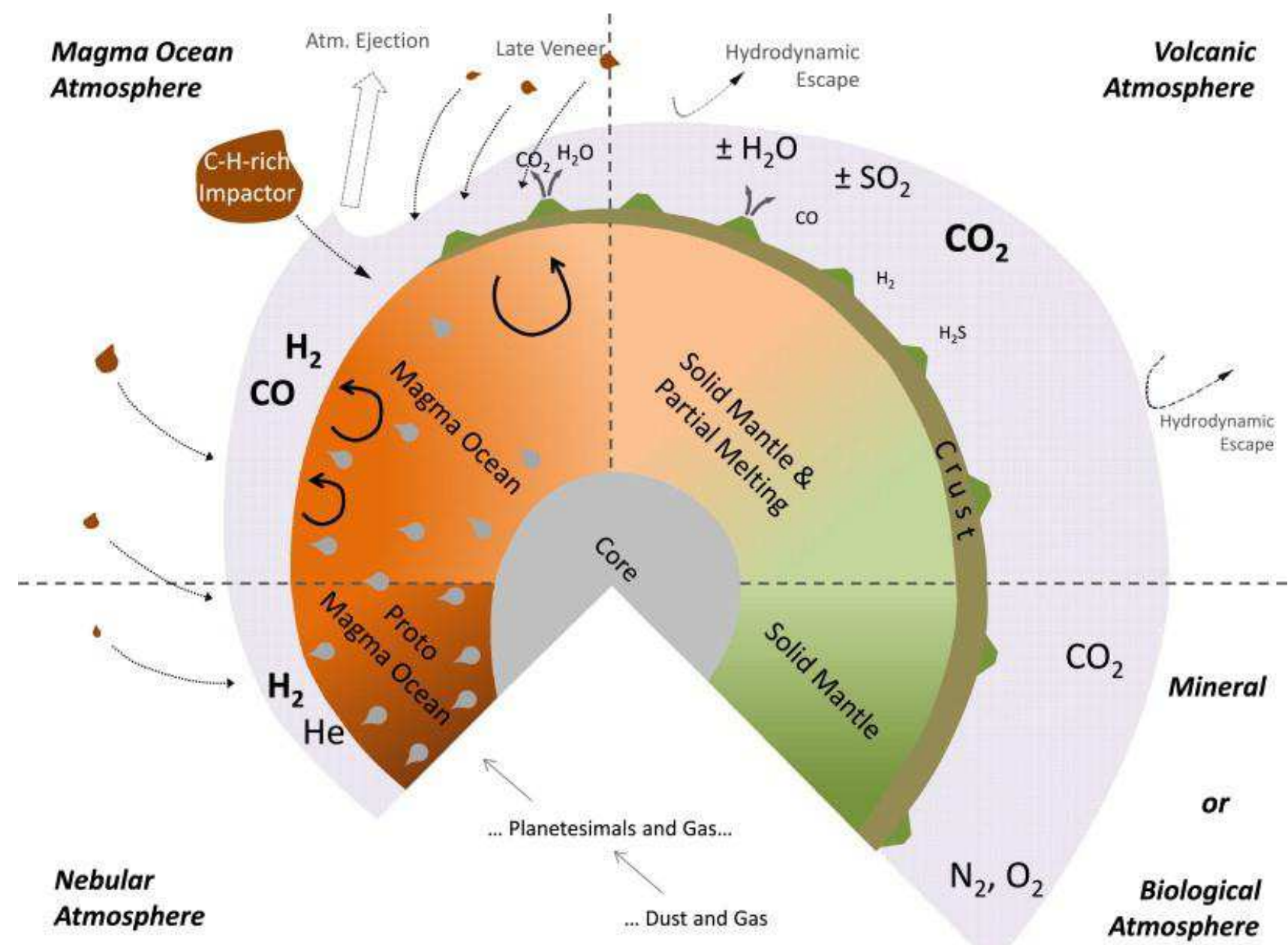

Fig. 1. The evolution of the planetary atmospheres. A helicoid projection illustrates the parallel growth of the planets and their atmosphere. For the planets, we present the magma ocean stage before and after core segregation, and the formation of the crust. For the atmosphere, we distinguished 4 successive types mostly inspired from (1): 1- the nebular atmosphere (planetesimal stage); 2- the magma ocean atmosphere (Hadean-stage of embryos and planets); 3- the volcanic atmosphere (inflated by volcanic gases); 4- Mineral or biological atmosphere (once volcanic activity slowed down and other processes take over such as biological pumps or mineral-gas equilibria). 


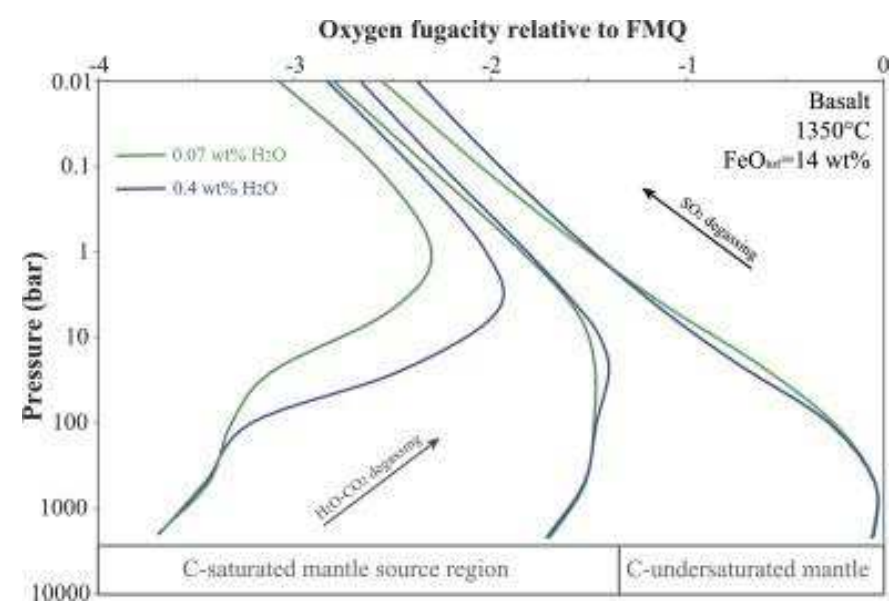

Fig. 2. The evolution of oxygen fugacity during degassing of basalts implies a planetary $\mathrm{fO}_{2}$ for degassing basalts. We have considered 6 cases, including 3 starting redox conditions inherited from 3 different source redox states ranging, from FMQ-4, a low value expected for the Martian mantle, to FMQ, which is admitted for the shallow Earth's upper mantle. For each initial redox conditions, we have considered water-enriched or -depleted cases. The overall conclusion is that $4 \log$-unit of differences in the $\mathrm{fO}_{2}$ of the basalt source regions only translate into about 0.5 log-unit at venting pressure. 


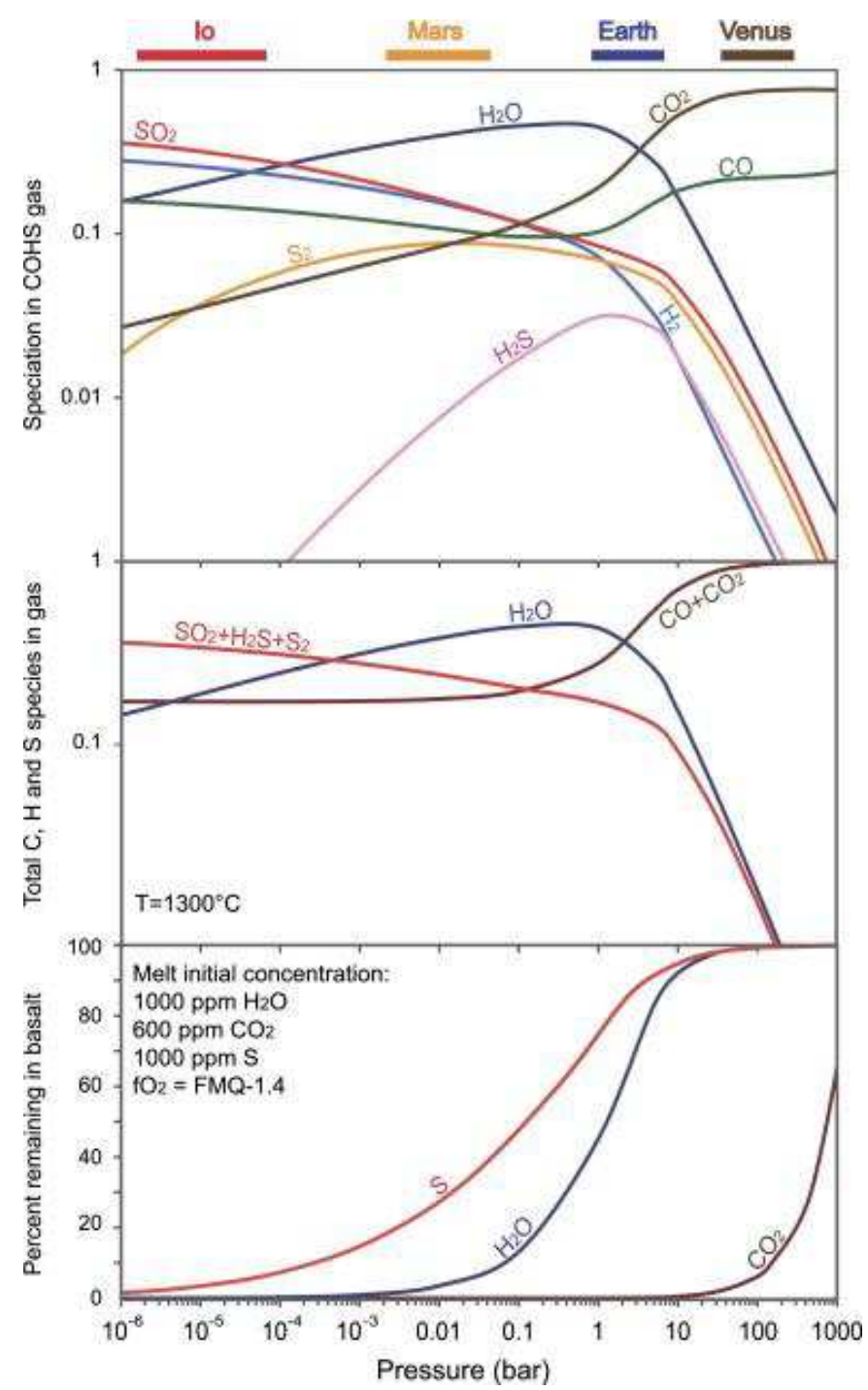

Fig. 3. Global chemical trends of basalt degassing in different planetary environments. A typical mid-ocean ridge basalts (MORBs) is considered to degas at pressure ranging from 1000 to $10^{-6}$ bar, which encompasses subaerial venting conditions expected to prevail on telluric bodies. Gas compositions were computed in the system C-O-H-S based on solubility laws for $\mathrm{H}_{2} \mathrm{O}, \mathrm{CO}_{2}, \mathrm{H}_{2}$ and $\mathrm{S}$ as explained in the text. The considered gaseous species, all related by thermodynamic constants, involve $\mathrm{H}_{2} \mathrm{O}, \mathrm{H}_{2}, \mathrm{CO}_{2}, \mathrm{CO}, \mathrm{CH}_{4}, \mathrm{SO}_{2}, \mathrm{~S}_{2}$, and $\mathrm{H}_{2} \mathrm{~S}$. The temperature of our simulation is $1300^{\circ} \mathrm{C}$. The pre-eruptive redox conditions are fixed at $1.5 \log$ units underneath that of the fayalitemagnetite-quartz, which is an average of redox state of basalts as recorded in the solar system on differentiated bodies. The total volatile abundances in the basalt are $600 \mathrm{ppm} \mathrm{CO}_{2}, 1000 \mathrm{ppm} \mathrm{H}_{2} \mathrm{O}$, $1000 \mathrm{ppm}$ S. The calculations we obtained suffer uncertainties of $10 \%$ and the choice of conditions as defined above does not significantly influence the trends we exemplify here. 


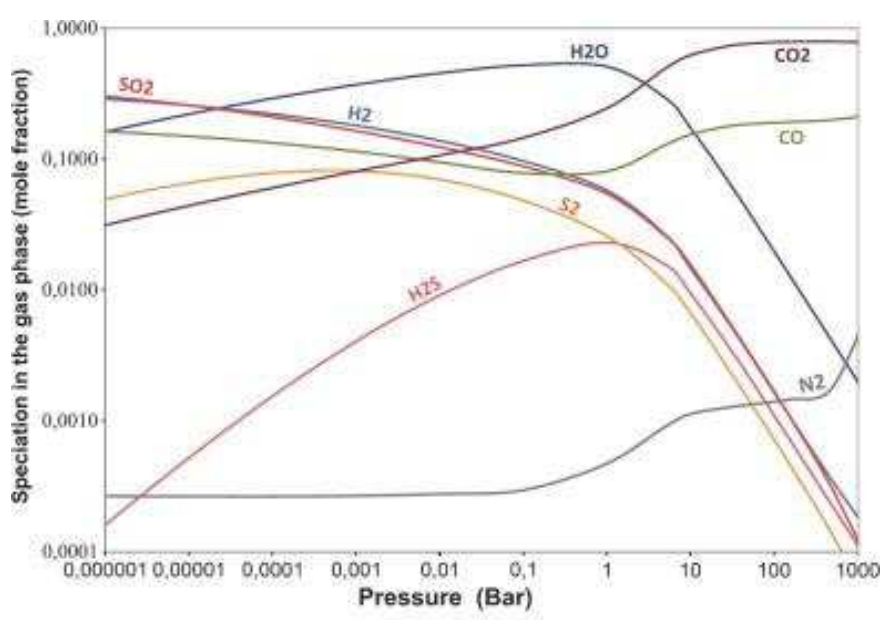

(a)

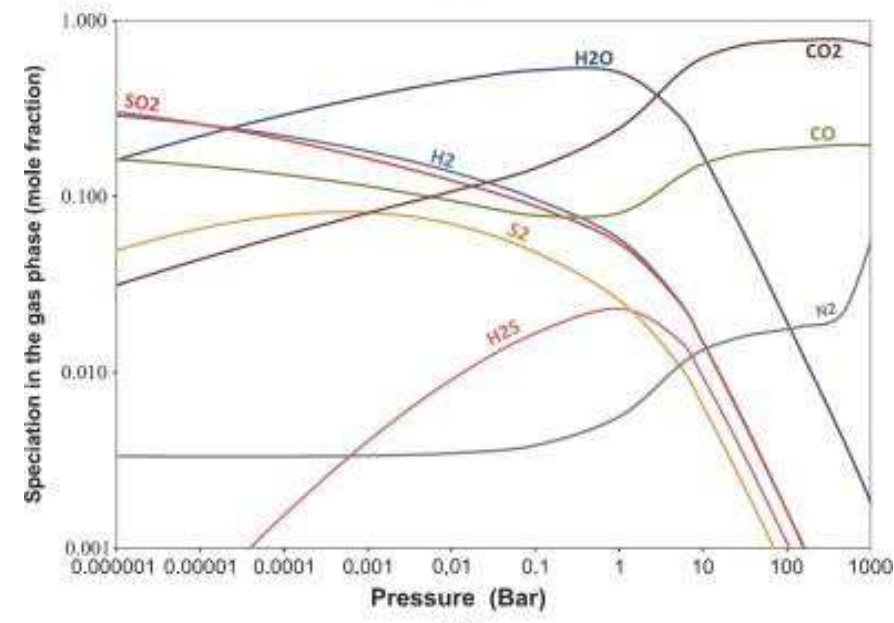

(b)

Fig. 4. The composition of volcanic gases in equilibrium with basalts in the C-O-H-S-N system as a function of pressure. The compositions and conditions are similar to those used in fig. 3 . The two panels show low (4a) and high (4b) nitrogen concentration in the magma.

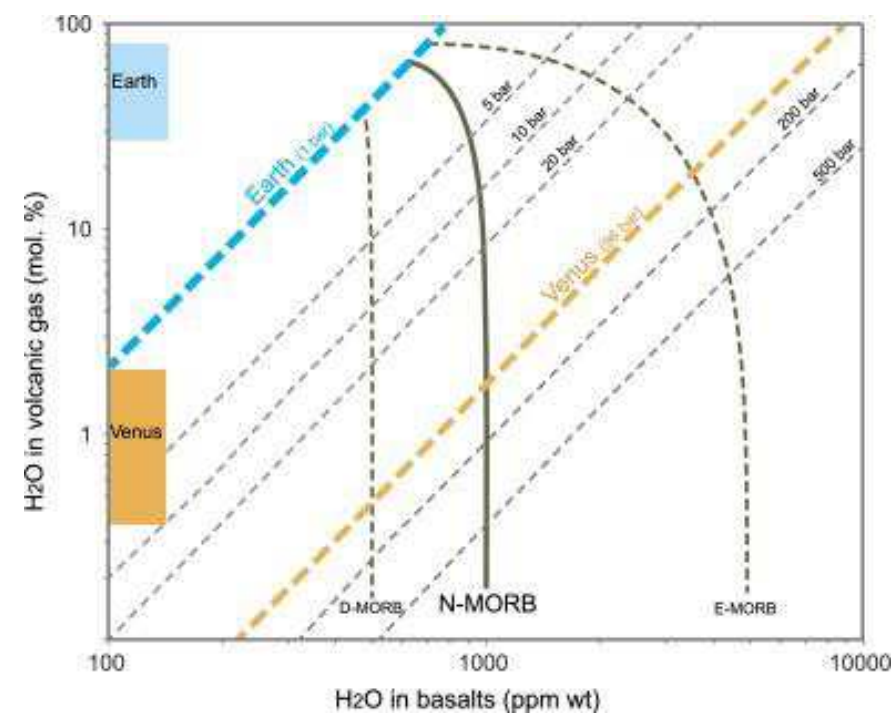

Fig. 5. The partitioning of water between basaltic melts and volcanic gases at $1200^{\circ} \mathrm{C}$. The horizontal axis shows ppm-wt $\mathrm{H}_{2} \mathrm{O}$ content dissolved in basalt and the vertical axis shows the equilibrium water percentage in the coexisting gas (which can be translated into $\mathrm{CO}_{2}$ by the 
relationships $\mathrm{CO}_{2} \%=100-\% \mathrm{H}_{2} \mathrm{O}$ ). The dashed straight lines illustrate partitioning for different prevailing pressures computed following (Iacono-Marziano et al., 2012), which calculates gas-melt equilibrium in the simplified $\mathrm{H}_{2} \mathrm{O}-\mathrm{CO}_{2}$ system. The blue and orange dashed straight lines respectively represent atmospheric pressure for Earth and Venus. Closed-system degassing of basalts having $\mathrm{H}_{2} \mathrm{O}-\mathrm{CO}_{2}$ concentration matching depleted $\left(500 \mathrm{ppm} \mathrm{H}_{2} \mathrm{O}\right)$, normal $\left(1500 \mathrm{ppm} \mathrm{H}_{2} \mathrm{O}\right)$ and enriched (5000 ppm $\mathrm{H}_{2} \mathrm{O}$ ) mid-ocean-ridge basalts are shown by the green curves. Degassing the Earth's atmosphere produces wet gases, whereas degassing in Venus's atmosphere produces dry gases. Degassing in an atmosphere of about 5 bar represents a sort of threshold for which volcanic gases contain $50 \%$ water. Higher atmospheric pressure would be conducive to dry volcanic emissions.

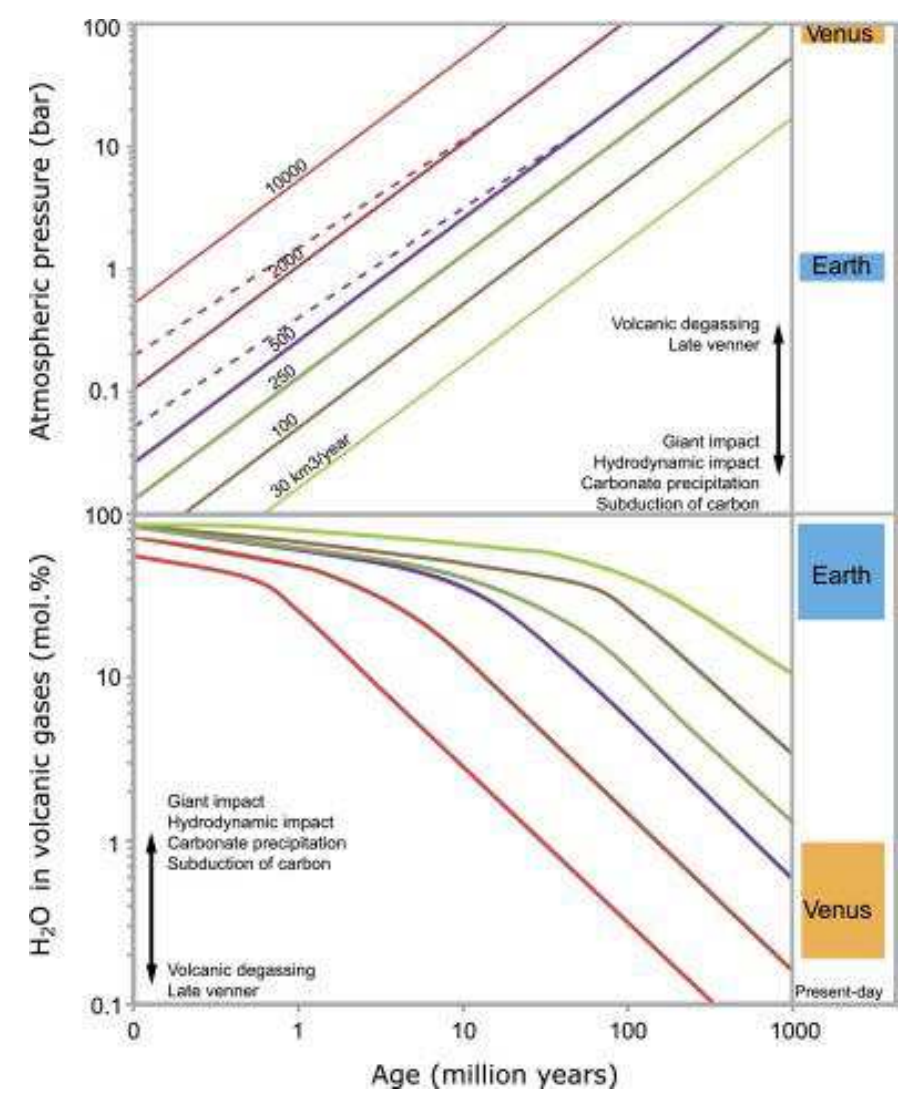

Fig. 6. The growth of the volcanic atmosphere and its impact on the runaway drying of volcanic gases. The top figure shows the increase in atmospheric pressure due to progressive degassing of basalts and the bottom figures show the equilibrium composition of volcanic gases through time. In both cases, the volatiles content in basalt is similar to that computed in Fig. 3. Different volcanic eruption rates are simulated from present day Earth $\left(30 \mathrm{~km}^{3} /\right.$ year $)$ to a quasi-magma ocean configuration (10000 $\mathrm{km}^{3} /$ year). Intermediate values correspond to an infant and hot planet. The atmospheric pressure versus time lines are calculated using (Grott et al., 2011), which remains a reasonable approximation for our purpose. Assuming a volcanic eruption rates about 10 times that of present-day Earth, volcanic outgassing would produce an atmosphere of 100 bar within a couple of 
$10^{8}$ years. In most case, the volcanic atmosphere is inflated by pure $\mathrm{CO}_{2}$, but equations in (29) can be modified to include water degassing. The effect of water is shown by the dashed lines that merge the full lines as atmospheric pressure exceed 10 bar. The reason is illustrated in Fig. 3, where degassing of water becomes insignificant at pressure exceeding 10 bar. In response to the increase in atmospheric pressure with time, the composition of volcanic gases will become drier as shown on the bottom plot; this is the runaway drying. This is only in the first $10^{7-8}$ years, that volcanic gases can be wet. The schematic vertical arrows indicate how any perturbations to the system (impact ejection, subduction and others) would allow a deviation from the runaway drying scenario.

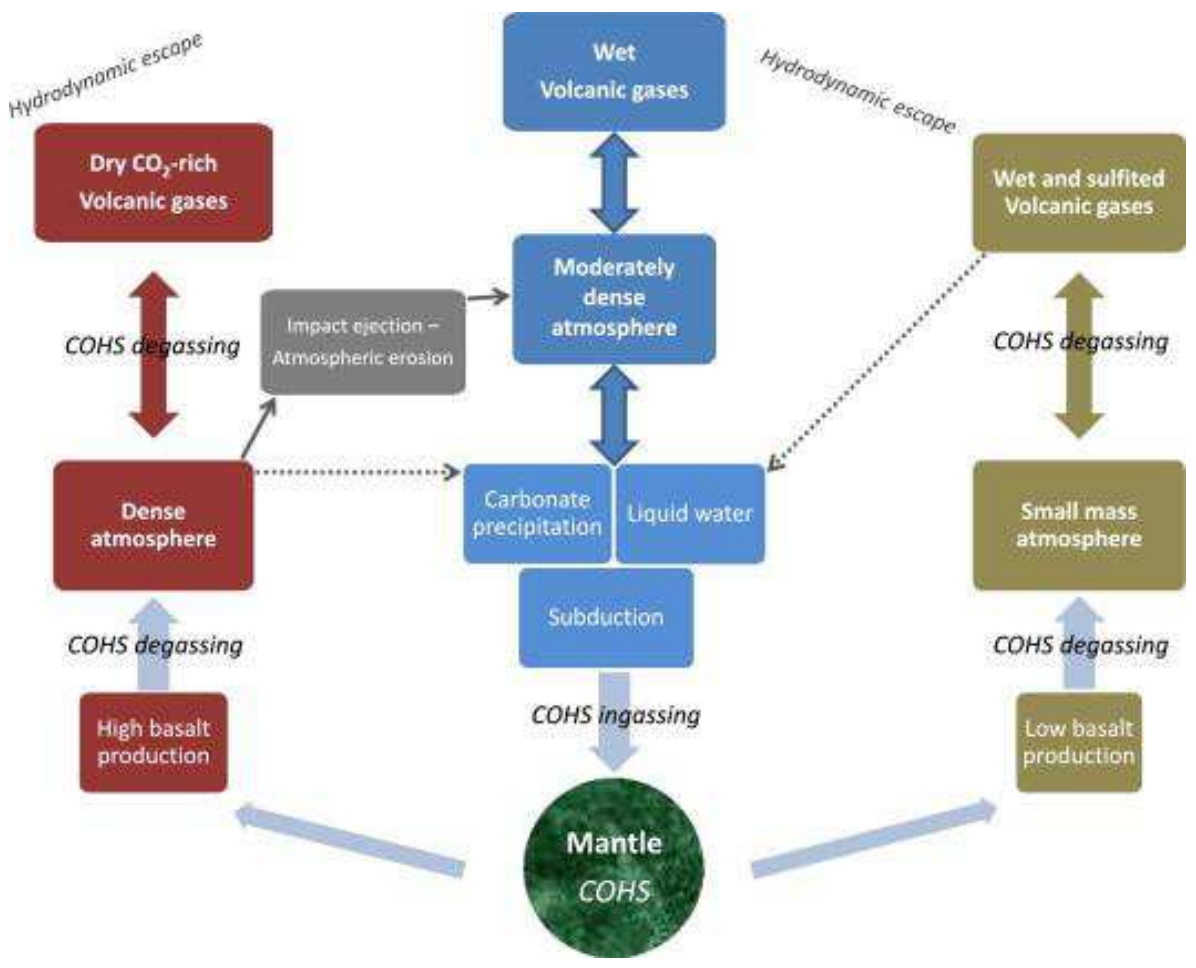

Fig. 7. Flowchart illustrating the interrelations between volcanic degassing and planetary atmospheric evolutions. The chain of processes is fully illustrated including: mantle melting, basalt degassing, atmospheric growth, atmospheric erosion, carbonate precipitation, return of volatiles in the mantle via subduction processes. High basalt production must lead to dense atmosphere, dry volcanic gases and runaway drying. Low basalt production in contrast triggers tenuous atmosphere, hydrated and sulfur rich volcanic gases. 


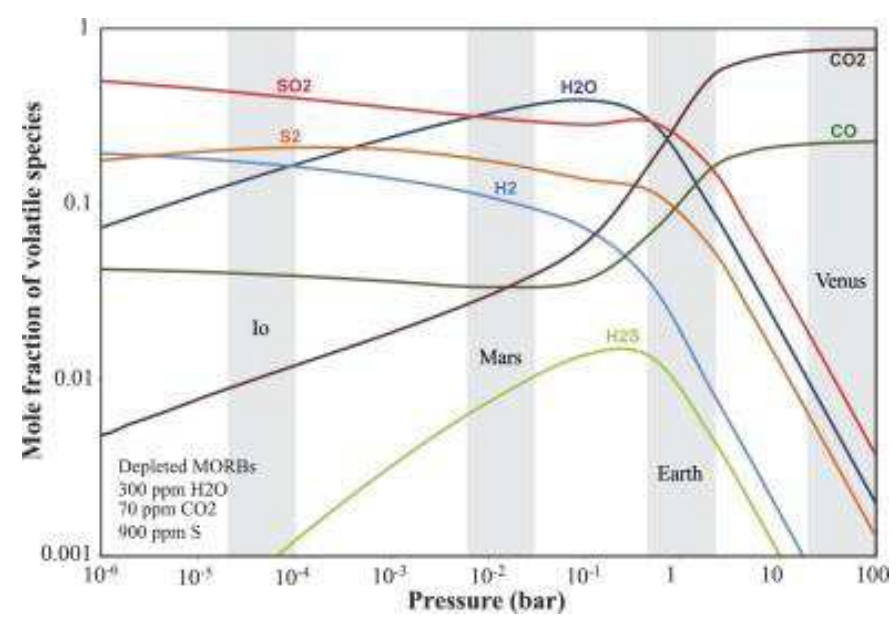

Fig. 8. Speciation in volcanic gases emitted by depleted MORBs as a function of pressure. At total pressure close to $10^{-4}-10^{-6}$ bar the $\mathrm{SO}_{2}$-rich gas becomes similar to that emitted by volcanic eruption on Io. Oxygen fugacity is FMQ-1.5 as expected for depleted-MORBs (see also Fig.3). Variation in the $\mathrm{SO}_{2} / \mathrm{S}_{2}$ ratio as intermittently observed for Ionian gas plumes can be reproduced considering variable oxygen fugacity ( $\pm 0.5 \mathrm{log}$ unit) or variable total iron contents in the basaltic source: more iron in the basalt at constant $\mathrm{fO}_{2}$ can increase the $\mathrm{SO}_{2} / \mathrm{S}_{2}$ ratio.

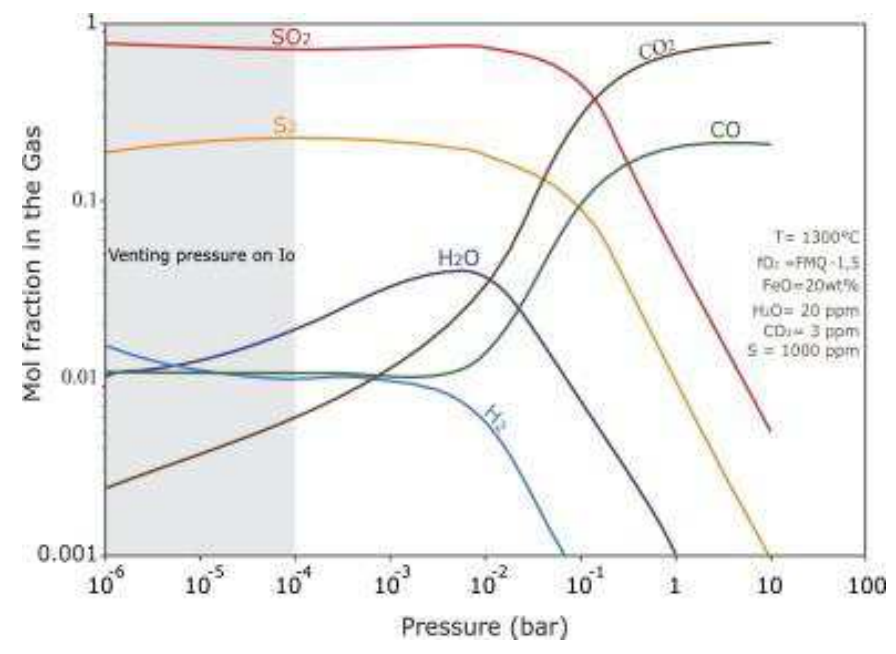

Fig. 9. Calculated volcanic gases emitted by basalts on Io. The composition of some of the volcanic gas plumes emitted on Io is reproduced at pressure of $10^{-4}$ bar considering basalts with pre-eruptive volatile contents of $3 \mathrm{ppm} \mathrm{CO}_{2}, 20 \mathrm{ppm} \mathrm{H}_{2} \mathrm{O}$ and $1000 \mathrm{ppm} \mathrm{S}$. This is close to the volatile contents of depleted MORB analyzed on Earth (Saal et al., 2002). Temperature is $1300^{\circ} \mathrm{C}$ and oxygen fugacity prior to degassing is fixed at FMQ-1.5 (Zolotov and Fegley, 1999). 